http://jmscr.igmpublication.org/home/ ISSN (e)-2347-176x ISSN (p) 2455-0450

crossref DOI: https://dx.doi.org/10.18535/jmscr/v8i11.11

Journal Of Medical Science And Clinical Research

\title{
A Clinical Study on Benefits of Early Enteral Feeding After Intestinal Resection and Anastomosis
}

\section{Authors \\ Dr R.Logesh Kumar ${ }^{1}$, Dr N.Junior Sundresh ${ }^{2 *}$, Dr D.Gopikrishna ${ }^{3}$, Dr P.Vigneshwaran ${ }^{4}$, Dr A.P.S.Gurupraveen ${ }^{5}$}

${ }^{1,4,5}$ Post Graduate, Dept of General Surgery, Rajah Muthiah Medical College and Hospital, Annamalai

Nagar, Chidambaram, India, 608002

${ }^{2}$ Professor, Dept of General Surgery, Rajah Muthiah Medical College and Hospital, Annamalai Nagar,

Chidambaram, India, 608002

${ }^{3}$ Associate Professor, Dept of General Surgery, Rajah Muthiah Medical College and Hospital, Annamalai

Nagar, Chidambaram, India, 608002

*Corresponding Author

Dr N.Junior Sundresh

Professor, Dept of General Surgery, Rajah Muthiah Medical College and Hospital, Annamalai Nagar, Chidambaram, India, 608002

Abstract
Background: As per conventional practice, post operatively after resection anastomosis of small and large intestine
patients are kept nil oral till bowel sounds appear. But early enteral feeding is beneficial to patients as per recent
studies. In This study we are comparing early enteral feeding vs nil by mouth for cases of intestinal resection and
anastomosis
Methods: The comparative study includes sixty cases of intestinal resection and anastomosis, in the post operative
wards of Rajah Muthiah Medical College and Hospital, Chidambram
during Oct 2018 to March 2020 , the cases are selected for study by randomized selection from which 30 patients
were kept nil by mouth and 30 patients started on early enteral feeding
Results: in this study the most common surgeries performed ileostomy. The patient started with early enteral feeding
found to have statistically lower incidence of surgical site infection, post operative ileus and shorter hospital stay.
Conclusion: In this study The patient started with early enteral feeding found to have statistically lower incidence of
surgical site infection, post operative ileus and shorter hospital stay. That concludes early enteral feeding is
beneficial in post operative patients of resection and anastomosis
Keywords: Enteral feeding, lleostomy, Intestines, Paralytic Ileus, Postoperative Pain, Surgical Anastomosis, Wound
Infection.

\section{Introduction}

Resection and anastomosis is often done in malnourished patients ${ }^{1-3}$ and in severe cases, is known to increase the post operative morbidity. ${ }^{4}$ Additionally these surgical patients are subjected to post operative stress and hypercatabolic state; hence these patients require some form of early nutrition, enteral or TPN. ${ }^{5}$ As per conventional practice, post operatively after resection anastomosis of small and large intestine patients are kept nil oral till bowel sounds appear. But early enteral feeding is beneficial to patients as per recent studies. Feeding post operatively within 24 hours is very safe and beneficial according to recent studies. ${ }^{6,7}$ 
Contrary to conventional opinion, evidence from clinical studies and animal experiments suggests that initiating feeding early is advantageous. In experimental studies found that starvation reduces the collagen content in anastomotic site and delays healing, ${ }^{9,10}$ whereas feeding reverses mucosal atrophy induced by starvation ${ }^{11}$ and increases anastomotic collagen deposition and strength. ${ }^{12}$ Finally, early enteral feeding may reduce post operative surgical site infections and gives less hospital stay.

\section{Methodology}

This is a prospective randomized comparative study was carried out at Rajah Muthiah Medical College, Chidambaram for a duration of 2 years (2018 till 2020). Totally sixty patients of intestinal resection and anastomosis included in the study. From sixty, 30 patients were randomly selected for nil by mouth and other 30 patients early enteral feeding postoperatively within $24 \mathrm{hrs}$ after taking written informed consent.

\section{Inclusion and Exclusion Criteria Inclusion criteria}

- Patients undergoing major abdominal surgeries either elective or emergency.

- Age group more than 12 years

\section{Exclusion criteria}

- Patients age group $<12$ years.

- Post operative patients requiring ventilator support.

- Pregnant women.

\section{Results}

Table 1: Procedures

\begin{tabular}{|l|c|c|c|c|}
\hline procedure & Case & Control & Case (\%) & Control (\%) \\
\hline Right hemicolectomy & 04 & 02 & 13.4 & 6.7 \\
\hline Left hemi colectomy & 01 & 01 & 3.3 & 3.3 \\
\hline IAanastomosis & 03 & 02 & 10 & 6.6 \\
\hline DJ anastomosis & 01 & 02 & 3.3 & 6.6 \\
\hline JJ anastomosis & 02 & 00 & 6.6 & 00 \\
\hline II anastomosis & 02 & 0.1 & 6.6 & 3.3 \\
\hline Ileostomy closure & 15 & 12 & 50 & 40 \\
\hline Colostomy closure & 06 & 08 & 20 & 26.6 \\
\hline
\end{tabular}

From this table the most commonly performed procedure is cases of ileostomy closure, in which case group contains 15 members and control contains 12 members.

Table 2: Complications

\begin{tabular}{|l|c|c|c|c|}
\hline Complications & Case & Control & Case (\%) & Control (\%) \\
\hline Anastamotic dehiscence & 01 & 01 & 3.3 & 3.3 \\
\hline Wound infection & 02 & 06 & 6.6 & 20 \\
\hline Pneumonia & 00 & 03 & 00 & 10 \\
\hline Intra abdominal abscess & 02 & 01 & 6.7 & 3.3 \\
\hline Vomiting & 01 & 02 & 3.3 & 6.7 \\
\hline Paralytic ileus & 01 & 09 & 3.3 & 30 \\
\hline
\end{tabular}

From this table wound infection is the common complication in this study both cases and control.

Table 3: Length of hospital stay

\begin{tabular}{|l|c|c|c|c|}
\hline Length of hospital stay (days) & Case & Control & Case (\%) & Control (\%) \\
\hline 06 & 00 & 00 & 00 & 00 \\
\hline 07 & 27 & 18 & 90 & 60 \\
\hline 08 & 00 & 00 & 00 & 00 \\
\hline 09 & 02 & 05 & 6.6 & 16.6 \\
\hline 10 & 01 & 01 & 3.3 & 3.3 \\
\hline 11 & 00 & 01 & 00 & 3.3 \\
\hline 12 & 00 & 02 & 00 & 6.6 \\
\hline 13 & 01 & 06 & 3.3 & 20 \\
\hline
\end{tabular}

From this table most of the patients (93\%) were discharged on seventh pod in case group. 


\section{Discussion}

In this study the most common procedure done was ileostomyclosure. Resection and anastomosis is often done in malnourished patients and in severe cases, is known to increase the post operative morbidity.4 Additionally these surgical patients are subjected to post operative stress and hypercatabolic state; hence these patients require some form of early nutrition, enteral or TPN. As per conventional practice, post operatively after resection anastomosis of small and large intestine patients are kept nil oral till bowel sounds appear. But early enteral feeding is beneficial to patients as per recent studies.

Feeding post operatively within 24 hours is very safe and beneficial according to recent studies. ${ }^{6,7}$ Contrary to conventional opinion, evidence from clinical studies and animal experiments suggests that initiating feeding early is advantageous. In experimental studies found that starvation reduces the collagen content in anastomotic site and delays healing, ${ }^{9,10}$

whereas feeding reverses mucosal atrophy induced by starvation ${ }^{11}$ and increases anastomotic collagen deposition and strength. ${ }^{12}$ Finally, early enteral feeding may reduce post operative surgical site infections and gives less hospital stay.

Anastomotic dehiscence is the most dreadful complication after intestinal resection and anastomosis. Wound infection is common complication after resection \& anastomosis of bowel, but antiobiotics reduced the incidence.

In this study wound infection is less in cases (enteral feeding) 2 cases than control group (nill by mouth) 6 patients. Which is statistically p value less than 0.05 which shows enteral feeding is beter.

In this study results was shown early enteral feeding have decreased wound infection rate with statistical significance. Functional inhibition of propulsive bowel activity, irrespective of pathologic mechanism is called ileus Many factors are believed to contribute to paralytic ileus, including intra operative bowel manipulation, anesthetic agents, peri operative use of narcotics and post operative sympathetic hyperactivity and electrolyte imbalance. Early enteral feeding induces bowel motility.

In this study, 1 patient (3.3\%) had paralytic ileus in case group and 9 patients $(30 \%)$ had paralytic ileus in control group, and the ileus was managed as conservative. $\mathrm{P}$ value was 0.038. Data suggested that early enteral feeding was found to decrease incidence of paralytic ileus.

In this study, most of the patients $(93.3 \%)$ were discharged on the 7 th postoperative day in case group, as patients had increased well being and less post operative complications. While in control group, 18patients (60\%) were discharged on 7th postoperative day, case 27 patients $(90 \%) \mathrm{P}$ value was $<0.05$ (significant) according to Levene's $\mathrm{T}$ test, which indicates early enteral feeding significantly decreased length of hospital stay after operation.

\section{Conclusion}

From this study it can be concluded that, early enteral feeding significantly reduces the incidence of wound infection, paralytic ileus in post operative patients of resection and anastomosis of intestine. Duration of hospital stay in the post operative patients of resection and anastomosis of intestine is very less in patients undergone early enteral feeding dueto less complications. So comparing with nil by mouth early enteral feeding is safe, effective with less complication in post operative patients of resection and anastomosis of small and large intestine however more study have to be done with larger cases

\section{References}

1. McWhirter JP, Pennington CR. Incidence and recognition of malnutrition in hospital. BMJ. 1994;308:945 -8.

2. Hill GL, Pickford I, Young GA, Schorah CJ, Blackett RL, Burkinshaw L, et al. Malnutrition in surgical patients: an unrecognised problem. Lancet. 1977;i:689 -92 . 
3. Lennard Jones JE(Ed). A positive approach to nutrition as a treatment. 1992. King's Fund Centre. 11-13 Cavendish Square, London W1M 0AN.

4. The Veterans Affairs Total Parenteral Nutrition Cooperative Study Group. Perioperative total parenteral nutrition in surgical patients. $N$ Engl $J$ Med. 1991;325:525 -2.

5. Catchpole BN. Smooth muscle and the surgeon. Aust N Z J Surg.1989;59:199 208.

6. Moss G. Maintenance of gastrointestinal function after bowel surgery and immediate enteral full nutrition. II. Clinical experience, with objective demonstration of intestinal absorption and motility. $J$ Parenter Enteral Nutr. 1981;5:215 -20.

7. McCarter MD, Gomez ME, Daly JM. Early postoperative enteral feeding following major upper gastrointestinal surgery. J Gastrointest Surg.1996;1:278 85.

8. Uden P, Blomquist $\mathrm{P}$, Jiborn $\mathrm{H}$, Zederfeldt B. Impact of long term relative bowel rest on conditions for colonic surgery. Am J Surg. 1988;156:381 -5.

9. Irvin TT, Hunt TK. Effect of malnutrition on colonic healing. Ann Surg.1974;180: $765-72$.

10. Ward MW, Danzi M, Lewin MR, Rennie MJ, Clark CG. The effects of subclinical malnutrition and refeeding on the healing of experimental colonic anastomoses. $\mathrm{Br} \mathrm{J}$ Surg. 1982;69:308 -10. Sheth, et al.: Early Enteral Feeding after Intestinal Resection and Anastomosis 5 International Journal of Scientific Study | June 2015 | Vol 3 | Issue 3

11. Goodlad RA, Al Mukhtar MY, Ghatei MA, Bloom SR, Wright NA. Cell proliferation, plasma enteroglucagon and plasma gastrin levels in starved and refed rats. Virchows Arch B Cell Pathol Incl Mol Pathol. 1983;43:55- 62.

12. Moss G, Greenstein A, Levy S, Bierenbaum A. Maintenance of GI function after bowel surgery and immediate enteral full nutrition. I. Doubling of canine colorectal anastomotic bursting pressure and intestinal wound mature collagen content. Clinical experience, with objective demonstration of intestinal absorption and motility. $J$ Parenter Enteral Nutr. 1980;4:535 -8.

13. Schroeder D, Gillanders L,Mahr K, Hill GL. Effects of immediate postoperative enteral nutrition on body composition, muscle function, and wound healing. $J$ Parenter Enteral Nutr. 1991;15:376 -83.

14. Burke, J.F.: The effective period of preventive antibiotic action in experimental incisions and dermal lesions. Surgery.1961;50:161.

15. Feltis, J.M., Hamet, H.F.: Use of prophylactic anti-microbial drugs to prevent postoperative wound infection. Am J. Surg.1967;114:867-70.

16. Schrock T.R., Deveney C. W., Dunphy J. E. "Factors contributing to leakage of small and large intestinal anastomosis", Ann. Surg. 1973;177:513-8.

17. Reissman P, Teoh TA, Cohen SM, Weiss EG, Nogueras JJ, Wexner SD. Is early oral feeding safe after elective colorectal surgery? A prospective randomised trial. Ann Surg. 1995;222:73 -7.

18. Livingston Eh, Passaro EP Jr. Post operative ileus, Digest dis. science.1990;35;121-32. 